\title{
PONTUAÇÃO E PROSÓDIA À LUZ DO CONCEITO DE HETEROTOPIA: UMA REFLEXÃO LINGUÍSTICO-DISCURSIVA SOBRE A ESCRITA
}

\section{PUNCTUATION AND PROSODY UNDER THE PERSPECTIVE OF HETEROTOPY: A LINGUISTIC AND DISCURSIVE REFLEXION ABOUT WRITING}

\author{
Geovana Soncin*
}

UNESP

\begin{abstract}
Resumo: A relação entre pontuação e prosódia é tema de discussão entre diferentes perspectivas teóricas no interior dos estudos linguísticos. Este texto, por sua vez, propõe interpretar a relação entre pontuação e prosódia à luz do conceito de heterotopia, teorizado por Foucault (2005 [1967]). Para tanto, orienta-se pela proposta analítica de que a linguagem é a heterotopia fundante do homem e da sociedade, apresentada em Corrêa (2012), trabalho que teve como objetivo investigar a produção do espaço e das espacialidades em textos escritos por pré-vestibulandos. A fim de ilustrar como se daria a relação entre pontuação e prosódia segundo a interpretação proposta, são analisados um anúncio publicitário e um texto produzido em ambiente escolar. Com a discussão desenvolvida, espera-se apresentar elementos que contribuam para uma reflexão linguístico-discursiva sobre a escrita de modo a caracterizar, no que diz respeito à pontuação, sua heterogeneidade constitutiva.
\end{abstract}

Palavras-chave: Heterotopia. Prosódia. Escrita. Pontuação.

\begin{abstract}
The relationship between punctuation and prosody is an issue discussed by different theoretical approaches in linguistic studies. In this paper, we aim to understand this relationship under the perspective of heterotopy, formulated by Foucault (2005 [1967]). Therefore, this study assumes the idea that language is the founding heterotopy of man and of society, as defended by Corrêa (2012) in a work that investigated the production of space and spatiality in pre-university written texts. In order to exemplify this perspective, we analyze an advertisement and a school text written by a student. We hope that the analysis we assume can contribute for linguistic and discursive discussion about writing in order to characterize its constitutive heterogeneity, especially in what concerns punctuation.
\end{abstract}

Keywords: Heterotopy. Prosody. Writing. Punctuation.

\section{INTRODUÇÃO}

A relação entre a organização prosódica da língua portuguesa e o emprego dos sinais de pontuação, particularmente o emprego da vírgula, é o principal eixo temático abordado em

\footnotetext{
* Doutora em Estudos Linguísticos, Professora vinculada ao Departamento de Fonoaudiologia, da Universidade Estadual Paulista “Júlio de Mesquita Filho” (Unesp), câmpus de Marília. E-mail: geovana.soncin@unesp.br.
} 
trabalhos anteriores (a saber, SONCIN, 2012, 2013; TENANI; SONCIN, 2009; SONCIN; TENANI, 2015, 2017a, 2017b), os quais apresentam aspectos de uma discussão teórico-analítica endossada em minha tese de doutorado (SONCIN, 2014). Nela, defendi que a prosódia - entendida não apenas em seu sentido formal, mas, de modo mais amplo, como meio de organização linguístico-discursiva dos enunciados concretos - constitui o emprego da vírgula de modo integrante, pois o ato de pontuar um texto com vírgula é efeito de processos simbólicos que se efetivam na escrita a partir de imagens sobre como a prosódia organiza e mobiliza sentidos. Esses sentidos, embora estejam cristalizados na língua, são atualizáveis nas situações enunciativo-discursivas em função da relação que o sujeito estabelece com a alteridade. Assim, considerando a dimensão que chamei de prosódico-enunciativa como condicionante da organização multidimensional dos sinais de pontuação - conforme proposta de Chacon (1998) da qual compartilho -, as análises apresentadas nos trabalhos referidos, de modo geral, tiveram por objetivo mostrar que as vírgulas marcam, no fio do discurso escrito, unidades prosódicas que denunciam os movimentos do sujeito por eixos de representação da língua, da escrita e da alteridade na busca por um sentido.

Ao desenvolver essa perspectiva, nossa proposta teórica se inseriu no debate existente na literatura linguística sobre a relação que os sinais de pontuação estabelecem com a dimensão fônica da linguagem: em termos mais amplos, sobre o que revela o funcionamento da pontuação no que toca a relação entre fala e escrita. Duas tradições teóricas majoritárias e contrárias entre si sustentam esse debate. Por um lado, os estudos de base fonocentrista - cujo expoente é Chafe (1987) - defendem que, em alguma medida, a organização prosódica da fala é representável na escrita, sendo os sinais de pontuação um dos meios para essa representação. Por outro lado, os estudos de base autonomista - cujo expoente é Anis (1988) - defendem a escrita como sistema primordialmente gráfico e autônomo em relação à fala e, por esse motivo, nessa perspectiva, os sinais de pontuação são definidos com base em regras de ordem gráfica e sintática, sendo desprezadas quaisquer informações de natureza prosódica. No interior desse debate, nossa posição não se filiou a uma ou outra tradição, pois compreendemos que ambas tratam da relação entre fala e escrita e, consequentemente, da relação entre prosódia e pontuação, com base em critérios de suficiência do gráfico em relação ao sonoro, quando o que está em jogo, em nosso ponto de vista, são os sentidos mobilizados pelos sinais de pontuação na escrita, tendo em vista o caráter simbólico que eles assumem ao guardarem em si o papel de organização linguística e enunciativo-discursiva da prosódia nos enunciados. Assim, explorando particularmente o emprego da vírgula, assumimos que "os sinais de pontuação representam a relação constitutiva entre prosódia e enunciação na escrita” (SONCIN, 2014, p. 62).

No entanto, apesar de ter defendido a existência de uma relação constitutiva entre prosódia e pontuação, assumindo uma visão enunciativa e discursiva de língua e de linguagem e de seus modos de manifestação - respectivamente fala e escrita, conforme propôs Corrêa (2004, 2013) -, não tratei qual seria o caráter dessa relação. Igualmente, nos estudos de pontuação, quando desenvolvidos em abordagens que consideram a relação deles com o domínio prosódico, observa-se uma lacuna sobre o estatuto teórico que assume essa relação. É, portanto, sobre essa questão que o presente artigo se propõe a discutir: em que consiste a relação constitutiva entre prosódia e pontuação? Como ela se estabelece no processo de escrita, tendo em vista o funcionamento mais geral da linguagem? 
Para investigá-la, trabalho com o conceito de heterotopia (e a relação que ele estabelece com o conceito de utopia), desenvolvido por Foucault (2005 [1967]), e, particularmente, com a aproximação entre o conceito de heterotopia e a própria linguagem, proposta por Corrêa (2012).

As seções do presente texto apresentam um percurso que traça a perspectiva teórica que proponho para compreender a relação entre prosódia e pontuação. Num primeiro momento, abordo os conceitos de heterotopia e utopia, mostrando os fundamentos teóricos que os sustentam, e a interpretação que Corrêa (2012) dá a eles no campo dos estudos da linguagem e da escrita. Num segundo momento, com base na contribuição desses dois autores, procuro associar o caráter simbólico da relação entre prosódia e pontuação ao conceito de heterotopia, considerando o espaço gráfico da pontuação na escrita como espaço no qual se encontram e se constroem outros espaços. Em seguida, exemplifico a proposta teórica sobre o caráter da relação em questão por meio da análise de um anúncio publicitário que teve como título "A vírgula” e, por fim, encerro o artigo fazendo considerações sobre os sinais de pontuação empregados em um texto escolar a fim de mostrar como a compreensão da relação proposta pode iluminar a compreensão da produção escrita escolar considerando o texto em seu funcionamento linguístico-discursivo.

\section{SOBRE O CONCEITO DE HETEROTOPIA E SUA RELEVÂNCIA PARA OS ESTUDOS DA LINGUAGEM}

Na conferência intitulada "De outros espaços”, proferida no Cercle d’Études Architecturales, Foucault (2005 [1967]) desenvolve uma reflexão sobre o espaço (ou melhor, sobre os espaços) e, de partida, avalia que a experiência do homem no mundo na era moderna "se assemelha mais a uma rede que vai ligando pontos e se intersecta com a sua própria meada do que propriamente a uma vivência que se vai enriquecendo com o tempo" (FOUCAULT, 2005 [1967], p. 1).

Ao tratar da intersecção de pontos em rede, Foucault (2005 [1967]) aborda a relação do homem com o espaço, pois, ligando pontos, a experiência humana faz recortes de diferentes espaços, que, ao se relacionarem e se entrecruzarem, formam uma trama própria. Entre outros aspectos sobre o espaço contemplados em sua fala - o que inclui a relação íntima que estabelece com o tempo -, o autor chama atenção para o fato de que os espaços se definem por meio das várias relações que estabelecem com a vida do homem na sociedade, o que lhes confere um caráter heterogêneo. Assim, o autor diferencia dois modos de conceber o espaço: como espaço interno ou como espaço externo.

Compreender o espaço segundo as relações que o definem é, pois, concebê-lo como espaço externo, como espaço “que nos leva para fora de nós mesmos” (FOUCAULT, 2005 [1967], p. 4). Diferente do espaço interno - no qual o espaço é concebido segundo o que os nossos sentidos permitem ver -, o espaço externo é aquele cuja descrição é possível em função das relações que o definem; como exemplo, o autor apresenta a rede de relações que definem ruas e ônibus como espaços de transporte, a rede de relações que definem cafés, cinemas e praias como espaços de relaxe temporário e a rede de relações que definem a casa, o quarto, a cama como espaços fechados ou semifechados. ${ }^{1}$

\footnotetext{
${ }^{1} \mathrm{O}$ autor utiliza a palavra "sítio" no interior dos termos sítios de transporte, sítios de relaxe temporário e sítios fechados ou semifechados.
} 
No desenvolvimento da discussão que contempla o espaço como marcado pelas relações que o definem, Foucault (2005 [1967]) dá um passo adiante: centra sua atenção em e faz formulações teóricas sobre os espaços que se relacionam com todos os outros espaços, “de forma que neutraliza, secunda, ou inverte a rede de relações por si designadas, espelhadas e refletidas. Espaços que se encadeiam uns nos outros, mas entretanto contradizem todos os outros” (FOUCAULT, 2005 [1967], p. 3). Tais espaços são conceituados pelo autor segundo duas categorias: a utopia e a heterotopia.

As utopias são espaços fundamentalmente irreais que apresentam relação analógica direta ou invertida com o espaço real da sociedade. Ao se manifestarem, apresentam a sociedade de forma aperfeiçoada ou, ainda, totalmente virada ao contrário (cf. FOUCAULT, 2005 [1967], p. 3). Por sua vez, as heterotopias, diferentemente das utopias, são espaços reais, que existem e se formam na própria fundação da sociedade. Segundo formula Foucault (2005 [1967]), as heterotopias são como contra-lugares, pois são espécies de utopias realizadas nas quais todos os demais lugares de uma dada cultura podem ser encontrados ao serem representados, contestados ou invertidos. Nas palavras do autor, esse tipo de lugar "está fora de todos os lugares, apesar de se poder obviamente apontar a sua posição geográfica na realidade” (FOUCAULT, 2005 [1967], p. 3).

Para o autor, porém, utopia e heterotopia não são espaços que se relacionam como uma dicotomia, pois entre elas pode existir um tipo de união ou mistura, exemplificada pelo autor por meio da figura do espelho e o modo como se dá seu funcionamento. Conforme a análise apresentada por Foucault (2005 [1967]), o espelho é, ao mesmo tempo, utopia e heterotopia.

Da perspectiva do espaço gerado por ele, o espelho é uma utopia, pois, tendo em vista a virtualidade da imagem que gera, é “um lugar sem lugar algum”. "No espelho, vejo-me ali onde não estou, num espaço irreal, virtual, que está aberto do lado de lá da superfície; estou além, ali onde não estou, sou uma sombra que me dá visibilidade de mim mesmo, que me permite ver-me ali onde estou ausente” (FOUCAULT, 2005 [1967], p. 3).

Porém, da perspectiva do efeito produzido pela imagem conjugada, o espelho é uma heterotopia, pois existe na realidade e "exerce um tipo de contra-ação à posição que eu ocupo" (FOUCAULT, 2005 [1967], p. 3), considerando que o “eu” ocupa ao mesmo tempo a posição de objeto e de observador. ${ }^{2}$ Como mostra o autor, ao observarmos nossa imagem no espelho, nos damos conta de nossa própria ausência no espaço em que nos encontramos na realidade, uma vez que nos vemos em outro espaço: irreal. A partir do olhar que dirigimos ao nosso reflexo, na imagem formada do lado de lá do espelho, voltamos a nós mesmos e passamos a reconstituir a nossa própria realidade no lugar em que de fato ocupamos. Assim, o espelho funciona como uma heterotopia no momento em que transforma este lugar, o que ocupo no momento em que me vejo no espelho, num espaço a um só tempo absolutamente real, associado a todo o espaço que o circunda, e absolutamente irreal, uma vez que para nos apercebermos desse espaço real, tem de se atravessar esse ponto virtual que está do lado de lá (FOUCAULT, 2005 [1967], p. 3-4, grifos nossos).

\footnotetext{
${ }^{2}$ Conforme apresentado no livro “Curso de Física”, de autoria de Antônio Máximo Ribeiro da Luz e Beatriz Alvarenga Álvares - Editora Scipione, 2000, 5 a edição, volume 2 - de acordo com os conceitos da óptica geométrica, a imagem virtual gerada pelo espelho comporta-se em relação ao observador como um objeto real.
} 
Dessa formulação, interpreto, com Corrêa (2012), a existência de "um funcionamento da heterotopia por meio do qual ela nos faz ver o lugar que, de fato, ocupamos, ao apontar para um espaço irreal, um ponto virtual que está em outra parte” (CORRÊA, 2012, p. 97). É considerando, pois, esse funcionamento, que Corrêa (2012) propõe uma aproximação entre o conceito de heterotopia e a própria linguagem. Consideremos sua proposta.

Na interpretação de Corrêa (2012) - da qual aqui compartilho - a linguagem é a heterotopia fundante do homem e da sociedade. Vejamos por que. Para tanto, trago excerto do texto por ele escrito:

O espelho "dá” a quem nele se mira a propriedade da reflexividade, analogamente ao que faz a linguagem em relação a si própria, pois, nas suas várias manifestações, ela sempre atualiza a função epilinguística. A linguagem, cuja propriedade fundamental, é referir (construir um lugar para os sujeitos e para o mundo) $e$ autorreferir-se (regramaticalizar-se pela relação com os sujeitos e com o mundo) é, nesse sentido, uma heterotopia. Assim como no espelho, a linguagem está, ao mesmo tempo, fora de si, lá onde dá uma existência particular aos sujeitos e ao mundo, lugar a partir do qual se refaz a si própria como espaço que, então, se transforma. Nesse sentido, a linguagem é uma utopia realizada, espaço fundante de todas as sociedades, lugar da experiência do espaço. É a essa experiência fundadora que retornamos quando precisamos materializar visualmente uma ideia ou um espaço. Na ciência como na arte, o recurso ao visível ou ao imaginado é frequentemente buscado como forma de tornar palpável o ainda desconhecido. Na medida em que a "heterotopia consegue sobrepor, num só espaço real, vários espaços, vários sítios que por si só seriam incompatíveis” (p. 10), pode-se afirmar que a linguagem é a heterotopia fundante do homem (é um homem falando que encontramos no mundo, um homem falando com outro homem, e a linguagem ensina a própria definição de homem” - BENVENISTE, 1976, p. 285) e da sociedade (o sentido nasce no intervalo entre subjetividade e alteridade) (CORRÊA, 2012, p. 97-98, grifos nossos).

Ao comparar a reflexividade do espelho ao funcionamento da linguagem, Corrêa (2012) chama atenção para o fato de que, em cada manifestação linguística, a linguagem se entrega ao uso dos sujeitos nas mais variadas situações de produção verbal sem perder (e, aliás, consolidando) sua integridade como lugar próprio para a construção da referência. Ao ser usada pelos sujeitos - e, assim, estar sujeita a eles - a linguagem atua fora de si, fora de seu eixo organizador sistêmico e simbólico. No entanto, a cada uso, a linguagem volta-se a si mesma para atuar sobre seu eixo organizador, o reorganizando, o ressignificando. É, portanto, por meio do acesso ao ponto que está do lado de fora que a linguagem encontra a si mesma e se refaz enquanto lugar real. Ao sujeitar-se aos sujeitos, ela ocupa um espaço no qual se pode ver e rever, conservar e mudar, se atualizar, se refazer.

Desse modo, a propriedade da linguagem de construir a referência, atuando fora de si junto à ação dos homens no mundo, consiste na experiência fundadora de criar espaços para designar outros espaços, dando a eles referência e concretude. A linguagem é, então, heterotopia, pois é o espaço que se relaciona com todos os espaços. Nesse sentido, a linguagem é a heterotopia fundante do homem, pois, por meio da necessidade de tornar simbólico um espaço, o homem o significa no espaço heterogêneo da linguagem e, assim, o concretiza ao lhe dar existência 
linguística - já que, sem a experiência fundante da linguagem, esse espaço é desconhecido e inapreensível. Por consequência, considerando que a sociedade é o espaço no qual os homens constroem relações simbólicas pela linguagem, concluímos, com Corrêa (2012), que a linguagem é também a heterotopia fundante da sociedade. A linguagem é o espaço que funda e sustenta a relação entre os homens em uma sociedade, cujos sentidos emergem do intervalo (marcado pelo conflito) entre subjetividade e alteridade - conforme menciona Corrêa (2012).

Tendo discorrido sobre a proposta de Corrêa (2012) de aproximar o conceito de heterotopia da própria linguagem, passo a relatar os desdobramentos dessa aproximação no exercício analítico feito pelo autor. Faço esse relato, uma vez que trilho caminho paralelo para pensar a relação entre prosódia e pontuação, discutida detalhadamente no próximo item. Interessado na relação íntima entre espaço e tempo, Corrêa (2012) faz dois exercícios interpretativos: analisa um texto jornalístico, num primeiro momento, e, em seguida, textos produzidos por pré-universitários em situação de vestibular.

Na análise do texto jornalístico, a atenção do autor se dirige ao modo como se apresenta a mudança qualitativa na relação que o homem estabelece com o espaço e com o tempo a partir da criação do mapa do metrô de Londres por Harry Beck em 1931. Modelo de mapa usado até hoje para orientar os usuários do metrô, conforme apresentado no texto jornalístico, a proposta do inglês foi a de espacializar no mapa os pontos da cidade ligados pelo metrô por meio de linhas retas, tendo em vista que, para a utilização desse meio de transporte, a direção e a relação das estações se tornaram informações mais importantes do que a própria localização geográfica. Na análise, Corrêa (2012) considera, de modo amplo, que todo mapa é uma heterotopia na medida em que, ao situar um território, faz remissão a outros territórios, determina direções e orienta movimentos; insere, assim, o território criado num espaço de relação com outros. No caso particular do metrô de Londres, Corrêa (2012) entende que a heterotopia se marca, na representação do espaço dada pelo mapa do metrô, pelo desejo de racionalizar o espaço urbano por meio do funcionamento do transporte metroviário: racionalização que se mostra na simplificação dos trajetos reais, na redução das distâncias e, também, na conversão de espaço em tempo, "fazendo do mapa o contenedor de uma experiência com o espaço em que está implicada a contenção de tempo-espaço” (CORRÊA, 2012, p. 100).

Nos textos de pré-universitários, por sua vez, o conceito de heterotopia orienta o olhar dado pelo autor ao uso de expressões de tempo e lugar. Segundo a análise do autor, esses operadores textuais, que funcionam enquanto "parcelas de tempo e espaço”, são heterotopias na organização do texto, tendo em vista que esses operadores apontam, simultaneamente, para fora do texto e para dentro dele, ou seja, estabelecem relações entre diferentes espaços a fim de construir o espaço textual. Ao apontarem para fora, indicam seu valor semântico no processo de construção dos “objetos do discurso”. Ao apontarem para dentro, expõem a organização formal do texto ao indicarem a relação que um dado operador estabelece com os demais (cf. CORRÊA, 2012, p. 104). Desse modo,

A construção dos objetos de discurso aponta para um exterior não totalmente determinado, já que ele só pode ser ratificado - ou, para fazer uso de uma formulação de Bakhtin (1992), só pode ter acabamento de sentido - em função do outro. Nessa aventura do sentido, esse espaço exterior é sempre, em alguma medida, desconhecido, e tem como correspondente, no espaço do texto (espaço do conhecido, “do real”), a exposição das articulações formais entre os operadores (CORRÊA, 2012, p. 104-105). 
Na visão do autor, portanto, a dinâmica heterotópica dos operadores textuais entre externo e interno, ou entre desconhecido e conhecido, ou, ainda, entre irreal e real, tem como efeito a produção dos sentidos no texto escrito na medida em que a construção espaço-temporal arquitetada por eles no interior do texto é significada quando entra em relação com o que está do lado de fora dele: o outro!... e sua constituição histórica.

\section{A PONTUAÇÃO COMO HETEROTOPIA NA CONSTRUÇÃO DO TEXTO}

Antes de discorrer sobre a relação entre pontuação e prosódia - principal objetivo do presente artigo - considerando as anotações teóricas apresentadas até aqui, faço breves considerações sobre o modo como tenho concebido o texto escrito, o sujeito escrevente e a produção dos sentidos que emerge da relação entre ambos.

Ancorando-me em Corrêa (2004, 2013), compreendo a escrita como modo de enunciação, o que significa considerá-la como "um dos modos de atualização da língua ou, ainda, como uma das maneiras de realização discursiva por meio das quais sujeito e sentido ganham forma" (CORRÊA, 2013, p. 290). Nessa concepção, a escrita é dotada do potencial de produzir sentidos ao ser permeada pela constituição histórica do sujeito nas mais variadas práticas de linguagem, sejam elas orais ou escritas.

Desse modo, não restrita à sua função de código de representação do falado, como é comumente considerada em diferentes espaços sociais (inclusive o escolar!), a escrita é, portanto, o lugar onde sujeito e sentido se encontram e, assim, como salienta Corrêa (2013), "não há relação dicotômica possível entre escrita e fala” (CORRÊA, 2013, p. 290), uma vez que toda e qualquer produção linguística do sujeito, seja ela falada ou escrita, trará marcas do seu processo de constituição social e histórica, que não existe fora da linguagem. Ou seja: o sujeito que escreve no momento presente da enunciação escrita é também, simultaneamente, o sujeito que fala em outras enunciações orais; do mesmo modo, o sujeito que fala no momento presente de uma enunciação oral é também um sujeito que escreve em outras enunciações escritas. Assim, sendo o sujeito cindido, heterogêneo por constituição, sua produção linguística, independente de seu modo de manifestação (entenda-se falado ou escrito, para citar apenas dois), será, por consequência, heterogênea. Não escapa dessa trama o fato de que o sentido mobilizado nas diversas produções linguísticas será igualmente heterogêneo e é acessado quando se considera a opacidade da língua e da linguagem e de seus modos de manifestação... nunca constituídos isoladamente.

No que tange à produção dos sentidos, como não poderia ser diferente, ela se constrói pela relação dialógica que o sujeito estabelece com o mundo. Nesse ínterim, os sentidos emergem na medida em que se manifesta a relação eu-outro; relação essa que, por ser constitutiva de toda manifestação de linguagem, inclui, necessariamente, a manifestação de linguagem que se dá via escrita. Assim, os usos da escrita são constituídos de relações entre o eu (que escreve) e o outro (que lê, seja ele real ou potencial por meio da projeção de uma imagem de interlocutor); em outras palavras, os usos da escrita são, portanto, assim como os usos da fala, espaços em que emergem intervalos entre a subjetividade e a alteridade.

Esses intervalos podem ser compreendidos por meio de relações entre verbal e extraverbal, partes essenciais do enunciado concreto, conforme conceituação de Voloshinov/Bakhtin (1976 [1926]). Considerando que, nesse quadro teórico, o enunciado concreto é a unidade real 
da comunicação discursiva, é pelo enunciado concreto que se manifestam os sentidos. Para tanto, verbal e extraverbal se vinculam por meio da atuação do sujeito do discurso de modo a dar expressividade às palavras ditas e, assim, criar a unidade real: o enunciado concreto. É por esse motivo que, de minha parte, proponho aqui que entendamos os intervalos entre a subjetividade e a alteridade pela ótica da relação entre verbal e extraverbal, uma vez que o extraverbal pode ser considerado como o horizonte espaço-temporal, marcadamente social e histórico, partilhado pelos interlocutores numa dada situação de comunicação, o qual conduz a(s) avaliação(ões) de ambos sobre a situação em que se encontram e sobre a qual enunciam. Resulta dessa posição avaliativa, da qual os sujeitos não escapam, o fato de que "a situação extraverbal se integra ao enunciado como uma parte constitutiva essencial da estrutura de sua significação” (VOLOSHINOV/ BAKHTIN, 1976 [1926], p. 6). Portanto, se, por um lado, o enunciado é forma verbal de língua, ele é igualmente significação extraverbal, definida pela relação dialógica entre pessoa-tempo-espaço. Desse modo, o extraverbal é parte presumida do enunciado concreto, sua faceta não enunciada em palavras, mas necessariamente presente e significativamente fundamental e sob a qual ecoam os dizeres dos outros e a avaliação que o “eu” faz delas.

Antes de passar a tratar dos sinais de pontuação nesse emaranhado teórico e desenvolver a proposta da heterotopia, falta um último aspecto a ser aqui apresentado: o papel da entoação expressiva. Em Voloshinov/Bakhtin (1976 [1926]) e em Bakhtin (2010), a menção à entoação expressiva ocorre para caracterizar o elo que une verbal e extraverbal e, assim, instaura o enunciado concreto. Esse elo - que diz respeito à própria entoação expressiva - é responsável por marcar a posição valorativa do locutor (falante) frente ao seu interlocutor e ao objeto do dizer. Nas palavras de Bakhtin:

Um dos meios de expressão da relação emocionalmente valorativa do falante com o objeto da sua fala é a entonação expressiva que soa nitidamente na execução oral - nós, evidentemente, a assimilamos como fator estilístico e na leitura muda de um discurso escrito. A entonação expressiva é um traço constitutivo do enunciado. No sistema da língua, isto é, fora do enunciado, ela não existe. Tanto a palavra quanto a oração enquanto unidades da língua são desprovidas de entonação expressiva. Se uma palavra isolada é pronunciada com entonação expressiva, já não é uma palavra, mas um enunciado acabado expresso por uma palavra (não há nenhum fundamento para desdobrá-la em oração) (BAKHTIN, 2010, p. 290, grifos nossos).

Vê-se, portanto, que a entoação, enquanto princípio constitutivo do enunciado concreto, tem a propriedade de atribuir significação ao que é dito por um locutor (falante) em uma situação comunicativa. Assim, ao se realizar, a entoação expressiva dá luz à posição assumida pelo falante: nas palavras de Corrêa (2013), ela permite acessar “a experiência social do falante”. Ao fazê-lo, a entoação dá o tom de acabamento ao enunciado e o coloca em condição de ser replicado por outrem, o reinserindo, consequentemente, na trama dialógica da linguagem. A entoação expressiva como propriedade do enunciado concreto me é cara, uma vez que concentra em si forma e substância: forma por ser materializável junto à voz na produção das palavras, orações ou quaisquer outras unidades linguísticas; e substância, pois traz em si e une às unidades linguísticas a complexidade da sociedade e dos valores cristalizados que nela existem à medida que expõe a posição valorativa do locutor. E é somente assim, enquanto forma material e substância imaterial, que a entoação expressiva transforma unidades da língua em enunciados concretos. 
Do lado da forma, a materialidade da entoação expressiva pode ser encontrada no conjunto do que se chama de aspectos prosódicos de uma língua, embora essa relação não seja, de forma alguma, correlata. ${ }^{3}$ Por aspectos prosódicos, costuma-se entender o conjunto de traços responsáveis por caracterizar o ritmo e a melodia das línguas (cf. LADD, 2014; MIRA MATEUS, 2005). Esses traços são, privilegiadamente: a intensidade, da qual resulta o acento; a duração, da qual resulta o ritmo; os tons, cuja combinação resulta nos contornos de entoação. Conforme procurei formular em trabalho anterior (SONCIN, 2014), a entoação expressiva não se trata da entoação em seu sentido estritamente prosódico, mas com ela se relaciona à medida que encontra, nos aspectos prosódicos, um meio material para promover a expressão ou, em outros termos, para dar o tom de acabamento ao enunciado, permitindo, então, acessar a posição assumida pelo falante.

Nessa elaboração que procurei fazer, os aspectos prosódicos são interpretados como eixo regulador de toda e qualquer produção de linguagem, pois assumem a função de organizar as unidades da língua ao mesmo tempo em que as inserem em processos de significação. Minha argumentação é, portanto, aquela de conceber que a prosódia não exerce papel acessório e não tem um fim em si mesmo. Ou seja, não é só forma, não atua apenas no plano formal da língua. Ao contrário, ela atua de modo a significar, a produzir significação. Prosódia é, portanto, o meio material pelo qual nuances de significação se expressam nos usos reais da língua. Obviamente, é possível considerar a prosódia metodologicamente como nível de análise linguística e, portanto, fora do seu uso real nas situações enunciativas. No entanto, não é essa a proposta que assumo neste texto particular. Proponho aqui pensarmos de maneira profunda e complexa no papel de significação que a prosódia desempenha ao mesmo tempo em que organiza as unidades linguísticas. Para Barbosa (2012), a prosódia é responsável por imprimir um "modo de falar" a "o que se fala". Mas quais modos de falar são esses? De minha parte, considero que esses modos são padrões e formas de língua cristalizados, repetidamente usados pelos sujeitos em situações de comunicação, tornando-os reconhecíveis e previsíveis. Tais formas cristalizadas são resultantes do já dito e evidenciam, assim, diversas posições valorativas já existentes, mas que são, a cada nova situação de uso real da língua, atualizadas, reanalisadas e ressignificadas pelo sujeito falante. Pensemos, por exemplo, em como conseguimos interpretar uma ironia ou uma palavra de ordem. Não é, primeiramente, pela atuação de aspectos prosódicos que se abre o caminho interpretativo?

Assim, a aproximação que faço entre o conceito bakhtiniano de entoação expressiva e aspectos prosódicos tem o objetivo de ressignificar, por um lado, o modo de conceber o papel da prosódia no funcionamento da língua e, por outro, vislumbrar um meio de materializar a entoação expressiva e o seu efeito na produção dos enunciados concretos. Conforme concluí em Soncin (2014, p. 56, grifos do original), "a entoação expressiva, longe de ser a entoação em seu sentido prosódico, é um trazer junto prosódia e vida, instaurando a relação entre materialidade linguística e memória por meio da presença do sujeito que a atualiza a cada vez que enuncia”.

A discussão que iniciei sobre o enunciado concreto e que culmina no entendimento sobre como a prosódia pode ser interessante para pensar o papel da entoação expressiva de dar, ao enunciado, um tom de acabamento faz-se relevante para o objetivo deste artigo, uma vez que a pontuação enquanto heterotopia pode ser concebida se consideramos que ela instaura no texto

\footnotetext{
${ }^{3}$ Essa é uma formulação que procurei desenvolver em termos teóricos em minha tese de doutoramento. Os interessados podem encontrar a discussão com os devidos detalhamentos em Soncin (2014).
} 
um espaço próprio de sinalização (o espaço de atuação dos sinais de pontuação) somente pela relação com outros espaços, por exemplo, o espaço sintático, o espaço gráfico e, certamente, o espaço prosódico. Assim, a pontuação é uma heterotopia, pois é um espaço do texto escrito em que se encontram múltiplos outros espaços. Não é por acaso que Chacon (1998) teoriza a pontuação como multidimensional, salientando que os sinais de pontuação são definidos por diferentes dimensões linguísticas: fônica, sintática, textual e enunciativa. Sob a ótica da heterotopia, compreendo a proposta do autor como meio de mostrar que a pontuação é o espaço da escrita onde se mostra a alternância de diversos espaços linguísticos.

Como o leitor já deve ter percebido, dentre esses espaços possíveis, desenvolvo a proposta da pontuação como heterotopia por meio da relação que a pontuação estabelece com a prosódia (o espaço prosódico). Não se trata, porém, de eliminar os demais espaços, como poderia ficar subentendido. Trata-se, na verdade, de compreender que a prosódia traz consigo e concentra em si a relação com os demais espaços. Evidências dessa afirmação se encontram, em primeiro lugar, na literatura especializada em prosódia, em cuja leitura se aprende como princípio básico que toda unidade prosódica se define pela relação com a sintaxe (cf. MIRA MATEUS, 2005; SELKIRK, 1984; NESPOR; VOGEL, 1986); em segundo lugar, nas descrições prosódicas de diferentes línguas (HALLIDAY, 1970; HIRST; DI CRISTO, 1998; D’IMPERIO et al., 2005; LADD, 2014) que apresentam o consenso de que a prosódia desempenha diversas funções: a) funções consideradas linguísticas, que são subdivididas em funções gramaticais ${ }^{4}$ e funções pragmáticas $^{5}$; e b) funções paralinguísticas, responsáveis por sinalizar aspectos emotivos e aspectos indexicais ${ }^{6}$ do falante, e, por fim, em terceiro lugar, no modo como aqui concebo a prosódia, inserida no âmbito da significação no interior das situações de enunciação, uma vez que, nesse viés, a prosódia atua no domínio enunciativo-discursivo, por meio de padrões prosódicos cristalizados que são mobilizados pelos sujeitos e assim significam ao recuperar dizeres e situações enunciativas anteriores para serem atualizadas. Como se pode ver, a prosódia se inter-relaciona com diversas dimensões e, nesse sentido, justifica-se minha proposta de conceber que a pontuação estabelece uma relação heterotópica com a prosódia: pois, nessa relação, a prosódia inclui outras relações com todos os demais espaços que também definem a pontuação.

A relação entre a pontuação e prosódia não é temática nova. Em meus trabalhos, particularmente, tenho defendido que a pontuação funciona como elemento organizador textual por atuar num domínio que chamei de prosódico-enunciativo, uma vez que, ao delimitar unidades do texto escrito - majoritariamente correspondentes a fronteiras prosódicas (cf. SONCIN, 2014; SONCIN; TENANI, 2015), - os sinais de pontuação organizam sentidos ao apontarem para a relação que essas unidades estabelecem com o extraverbal. Eis aí a escrita como enunciado concreto! Nessa concepção teórica, os sentidos são mobilizados pelos sinais de pontuação na escrita tendo em vista o caráter simbólico que eles assumem ao guardarem em si o papel de organização linguística e enunciativo-discursiva da prosódia nos enunciados. Assim, “os sinais de pontuação representam a relação constitutiva entre prosódia e enunciação na escrita” (SONCIN, 2014, p. 62).

\footnotetext{
${ }^{4}$ São consideradas gramaticais as funções de segmentação do enunciado e de marcação de proeminência, como o foco prosódico. ${ }^{5}$ São consideradas pragmáticas as funções de organização de turnos conversacionais e de indicação de força ilocucionária.

${ }^{6}$ Enquanto aspectos emotivos são aqueles que indicam as emoções e atitudes do falante frente ao que é dito, os aspectos indexicais são aqueles que permitem identificar um falante ou uma categoria de falantes. Essa última é a perspectiva desenvolvida pela Fonoestilítica.
} 
Considerando a função de organização textual dos sinais de pontuação na escrita, a pontuação, de modo similar ao funcionamento das expressões de tempo e espaço analisadas por Corrêa (2012), aponta, simultaneamente, para fora do texto e para dentro dele. No movimento para fora do texto, a pontuação indica o espaço no qual se circunscrevem os sentidos mobilizados (em alguma medida, sempre imponderáveis). No movimento para dentro do texto, a pontuação manifesta seu caráter de organizador formal, tanto na delimitação de unidades linguísticas quanto na segmentação do espaço gráfico no qual se constrói a unidade textual, na medida em que, ao delimitar uma unidade e segmentar uma porção gráfica, as insere na relação com as demais unidades e porções que compõem a unidade textual (unidade de caráter imaginário frente à dispersão discursiva). Nesses dois movimentos, interpreto que a pontuação recupera e atualiza o componente prosódico da língua, estabelecendo com ele uma relação de natureza heterotópica.

No primeiro movimento - em direção ao exterior do texto, ao extraverbal -, a pontuação reconstrói aspectos prosódicos de modo a situar a expressividade desses aspectos na cena enunciativa pela atuação do sujeito, que tenta produzir significação ao trazer ao seu dizer outros dizeres já existentes. Nesse movimento, os aspectos prosódicos que a pontuação marca na escrita são responsáveis por produzir significação à medida que evidenciam o dizer do sujeito, ou melhor, o seu modo de dizer, ao recuperar modos de dizer anteriores, cristalizados em outras práticas de linguagem, especialmente em práticas de oralidade. ${ }^{7}$

No segundo movimento - que se volta para o próprio texto -, a pontuação marca na escrita a atuação da prosódia no eixo da organização formal das unidades colocadas lado a lado no espaço textual. Delimita, assim, em que medida essas unidades estão unidas ou separadas e de que modo se relacionam, ou seja, até que ponto essas unidades delimitadas atuam sobre e com as demais. Nesse movimento, a pontuação circunscreve no texto escrito um espaço real, um espaço concreto para o espaço que se manifesta fora do texto: o espaço prosódico.

Considerando a dinâmica da pontuação realizada no entremeio entre esses dois movimentos na construção textual, é possível dizer que a pontuação está fora de si e é reconhecida quando se considera o "ao redor", aquilo que está para além de seus limites no texto e que, ao mesmo tempo e contraditoriamente, trata-se do que ela aponta de fato. No meu entender aqui desenvolvido, a pontuação é o espaço fundante no texto para a representação prosódica, já que o espaço criado pela pontuação reconstrói outro espaço - aquele do prosódico. Nessa reconstrução, que se mostra do lado de lá do texto, consegue-se perceber o lugar ocupado pela prosódia no espaço do uso real da língua: o de significar! Considerando a analogia do espelho, feita por Foucault (2005 [1967]), para pensar o papel da pontuação na construção do texto, o lado de lá, lado do irreal, é o lado da atuação da prosódia, a partir do qual a pontuação se reconhece do lado de cá, construído na superfície textual como espaço real.

Nesse sentido, proponho aqui que pensemos a relação entre pontuação e prosódia, tão polemizada em diversos estudos, como uma relação da ordem da heterotopia. Não se trata de identidade, não se trata de correlação, não se trata de exclusão, não se trata de interferência, mas se trata, do ponto de vista que assumo, de construção de espaços que se relacionam heterotopicamente entre si, pois a pontuação enquanto espaço real chama para si a prosódia e o

\footnotetext{
${ }^{7}$ A esse respeito, lembremos que o sujeito é atravessado por práticas de oralidade e de letramento, assim, sua produção de linguagem é heterogênea, dotada de aspectos de um e de outro modo de manifestação linguística: o falado e o escrito.
} 
que ela traz consigo, reunindo diferentes espaços num só. Desse modo, retomo as palavras de Corrêa (2012) aqui já elucidadas:

Na ciência como na arte, o recurso ao visível ou ao imaginado é frequentemente buscado como forma de tornar palpável o ainda desconhecido. Na medida em que a "heterotopia consegue sobrepor, num só espaço real, vários espaços, vários sítios que por si só seriam incompatíveis (p. 10), pode-se afirmar que a linguagem é a heterotopia fundante do homem [...] e da sociedade [...] (CORRÊA, 2012, p. 97-98, grifos nossos).

Com essa retomada das palavras do autor, busco argumentar que a pontuação seria o espaço real buscado na escrita para tornar palpável o espaço da prosódia, espaço pouco concreto e, em alguma medida, não transparente e menos conhecido, embora usado constantemente pelos sujeitos. Assim, a pontuação enquanto heterotopia sobrepõe outros espaços, mesmo que, aparentemente, esses pareçam incompatíveis. Baseando-me, portanto, na formulação de Corrêa (2012) que trata da linguagem como heterotopia, conceituo aqui que a dinâmica heterotópica da linguagem se manifesta também no papel que a pontuação exerce no texto escrito, atravessada pela prosódia... entendida enquanto forma e substância, ou seja, em seu funcionamento linguístico-discursivo.

\section{O CASO DE UM ANÚNCIO PUBLICITÁRIO}

A seguir, procuro explorar como a relação heterotópica entre pontuação e prosódia pode ser observada em campanha publicitária que teve como mote o emprego da vírgula. Trata-se da campanha em comemoração aos 100 anos da Associação Brasileira de Imprensa (ABI), veiculada em 2008, ano em que a associação completou seu centenário. Fez parte da campanha o anúncio publicitário, intitulado “A vírgula”, apresentado em formato impresso e em formato audiovisual. $\mathrm{O}$ anúncio publicitário impresso pode ser visualizado na imagem abaixo. O vídeo é de domínio público e pode ser acessado por meio do link: http://www.youtube.com/ watch?v=uWKpx5Ls1zg (último acesso em: 12 jul. 2020). 
Imagem 1: Anúncio publicitário impresso da campanha de 100 anos da ABI

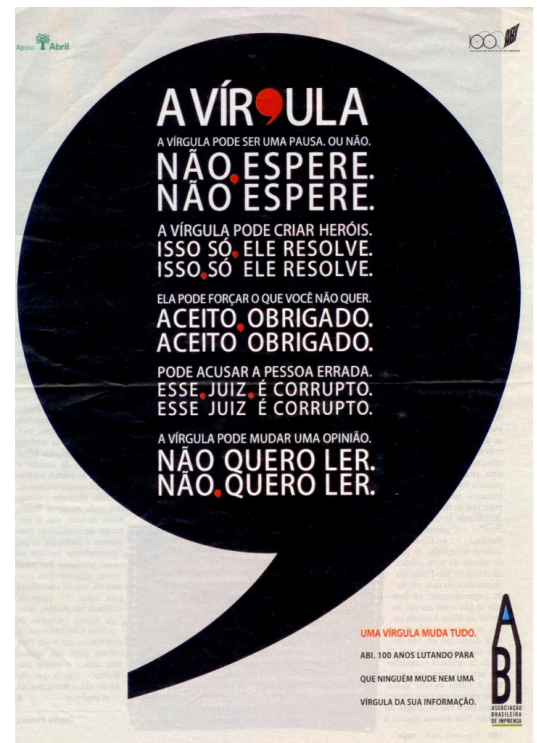

Transcrição do anúncio A vírgula

A vírgula pode ser uma pausa. Ou não. Não, espere. Não espere.

A vírgula pode criar heróis.

Isso só, ele resolve. Isso, só ele resolve.

Ela pode forçar o que você não quer. Aceito, obrigado. Aceito obrigado.

Pode acusar a pessoa errada. Esse, juiz, é corrupto. Esse juiz é corrupto

A vírgula pode mudar uma opinião. Não quero ler. Não, quero ler.

Uma vírgula muda tudo. ABI: 100 anos lutando para que ninguém mude nem uma vírgula da sua informação.

Fonte: Associação Brasileira de Imprensa. Disponível em: https://diarioh8.wordpress.com/2010/12/04/a-virgula-abi/ https://diarioh8.wordpress.com/2010/12/04/a-virgula-abi/Acesso em: 13 jul. 2020.

O anúncio publicitário é construído por meio da comparação de sentenças que se distinguem, do ponto de vista da organização textual, pelo emprego da vírgula; no entanto, considerando as sentenças contrastadas do ponto de vista da estrutura linguística, cada possibilidade de pontuação apresentada equivale a uma organização prosódica, que, por sua vez, identifica uma organização sintática particular. Assim, as sentenças comparadas são distintas em sua estruturação prosódica ao mesmo tempo em que se diferenciam na estrutura sintática. Dessas distinções, resultam diferentes possibilidades de interpretação semântica, fato que é explorado na propaganda a fim de mostrar o papel da vírgula de poder alterar os sentidos.

A fim de exemplificar a correlação feita entre unidades delimitadas pela vírgula e unidades delimitadas pela prosódia, tomemos como exemplo as sentenças Não, espere e Não espere. Enquanto a primeira pode ser representada prosodicamente como duas partes - [não] [espere] -, onde, para cada espaço delimitado pelos colchetes, projeta-se a realização de um contorno entoacional, totalizando, portanto, dois contornos distintos; a segunda é representada como uma única unidade - [não espere] - sendo projetado um único contorno. Dito isso, consideremos que, se sobrepusermos a representação gráfica à representação prosódica dessas sentenças, concluímos que: em uma estrutura, a delimitação feita pela presença da vírgula marca um limite prosódico entre duas unidades (representado pelos colchetes) e, por oposição, na outra estrutura, a ausência da vírgula marca a ausência de limite entre as unidades que estão em contiguidade. Em outros termos, podemos dizer que, na primeira estrutura, a vírgula marca a descontinuidade de relação entre não e espere, enquanto, na segunda estrutura, o espaço em branco (a ausência da vírgula, portanto) marca a relação de continuidade entre os mesmos elementos no eixo sintagmático. Tais continuidade e descontinuidade prosódicas refletem, noutro plano, as continuidades e descontinuidades no nível sintático. 
Desse modo, o papel desempenhado pela pontuação nas sentenças usadas pela propaganda não é outro a não ser aquele de apontar para o que ocorre prosodicamente nessas sentenças, especialmente porque nada se altera na cadeia segmental, ou seja, nada se altera na sequência de palavras: trata-se do mesmo, mas com estruturas diferentes. Assim, cabe à prosódia o papel de sinalizar como interpretar sintática e semanticamente essas estruturas.

O papel da prosódia é evidenciado no formato audiovisual do anúncio, uma vez que cada sentença é apresentada na tela visualmente em formato escrito, com sua devida pontuação, ao mesmo tempo em que se ouve uma produção sonora para tal sentença. Desse modo, no vídeo, a simultaneidade de apresentação da forma gráfica e da forma sonora orienta a conclusão de que, para cada uso da vírgula, corresponde uma configuração prosódica diferente e, por consequência, uma possibilidade de interpretação semântica distinta, evidenciando a relação entre o que se escreve (por meio da manifestação gráfica da pontuação), o que se ouve (em termos de configuração prosódica) e o que se pode interpretar (em termos de significação). Com isso, o anúncio explora o jogo de possibilidades interpretativas que podem ser sinalizadas no texto escrito pelo espaço criado pela pontuação, mas que, na verdade, se estabelecem fora dela, em outro(s) lugar(es): no espaço prosódico e o que mais ele mobiliza, o que inclui a sintaxe.

Tratando o anúncio publicitário como enunciado concreto, sua faceta verbal, organizada pela comparação de sentenças conforme procurei descrever anteriormente, produz sentido na medida em que se une à sua faceta extraverbal. A repetição de sentenças que se diferenciam pelo uso da pontuação é usada como meio de argumentar favoravelmente à importância da Imprensa na sociedade civil por se tratar de instituição que valoriza o ofício de divulgar informações com transparência e racionalidade e, por isso, tem apreço ao modo como tais informações são apresentadas à população. Assim, no anúncio, enfatiza-se o valor de preciosidade que a Associação Brasileira de Imprensa atribui à escrita, uma vez que a instituição reconhece que cada marca gráfica, por menor que seja, como é o caso da vírgula, tem valor preponderante para a construção de um texto e, consequentemente, para a(s) informação(ões) que esses textos disseminam, podendo, assim: “criar heróis”, "mudar uma opinião", "acusar a pessoa errada”... “mudar tudo”. É por meio dessa argumentação que a propaganda atende ao que se propôs: defender o importante papel da Imprensa na sociedade e, assim, justificar e comemorar a existência da Associação Brasileira de Imprensa ao longo de um século, a qual atua na luta para que "ninguém mude nem uma vírgula da sua informação", ou seja, para que nenhum sentido seja alterado, obscurecido, apagado. A responsabilidade atribuída no anúncio à Associação Brasileira de Imprensa de lutar pela transparência e suposta imparcialidade das informações veiculadas pela Imprensa Brasileira ganha peso e relevância se considerarmos que tal associação atua em um país que sofreu graves golpes à liberdade de expressão e à liberdade de Imprensa ao longo do período de ditadura militar, durante o qual os documentos jornalísticos, cuja circulação era autorizada, podiam ser deliberadamente alterados por órgãos de Estado para fins de manutenção do poder por meio de estratégias de manipulação social. Cabe ainda dizer que os sentidos produzidos por esse anúncio publicitário se renovam se considerarmos os dias atuais em que vivemos, ${ }^{8}$ quando a democracia brasileira volta a sofrer episódios de ataque e

\footnotetext{
${ }^{8}$ Refiro-me especificamente aos anos de governo do presidente Jair Bolsonaro, conhecido por seus ataques diretos a jornalistas durante entrevistas e a órgãos de imprensa que apresentem críticas às suas ações governamentais e ao seu comportamento, bastante questionável (diga-se de passagem), enquanto presidente da República. Vale mencionar ainda as recorrentes e ameaçadoras falas do então presidente que colocam em cheque evidências científicas e fatos históricos, que foram e são divulgados por órgãos de imprensa e/ou por outros veículos que divulgam informações desse tipo, de valor imensurável à população brasileira por permitir acesso a dados verídicos sobre a(s) realidade(s) do Brasil.
} 
quando muitos órgãos de imprensa passam a ter sua liberdade afunilada e veracidade de suas informações questionadas por meio, por um lado, de ameaças veladas e, por outro, por meio da rápida disseminação de notícias fantasmas com conteúdos falsos que chegam à população como verdades e que dificultam a avaliação do que é confiável ou não.

Vejamos: o modo como interpretamos esse anúncio publicitário é resultado do elo entre verbal e extraverbal, sendo que a parte verbal é marcada pela relação entre pontuação e prosódia, relação essa de natureza heterotópica, já que o espaço criado pela pontuação no anúncio permite a recuperação de outros espaços que atuam fora do texto e que encontram, na prosódia, a abertura para os caminhos interpretativos cuja referência é buscada no extraverbal.

\section{O CASO DE TEXTOS ESCOLARES}

Para finalizar a proposta que desenvolvo neste texto, procuro neste item exemplificar a relação heterotópica entre pontuação e prosódia com a análise de um texto escolar. Trata-se de texto extraído do Banco de Dados de Escrita do Ensino Fundamental II, disponível online, ${ }^{9}$ formado por textos escritos por alunos do segundo ciclo do Ensino Fundamental de uma escola pública da cidade de São José do Rio Preto, no noroeste paulista.

O texto particular que analiso foi redigido, em 2008, por aluno de $8^{\mathrm{a}}$ série (atual $9^{\circ}$ ano), a partir de proposta de produção textual que solicitava a escrita de uma carta sobre as vantagens e desvantagens da escola onde estudava, endereçada à pesquisadora que aplicou a proposta durante oficina de produção textual. Consideremos o texto.

Imagem 2: Texto escolar produzido por aluno de 8º série do Ensino Fundamental

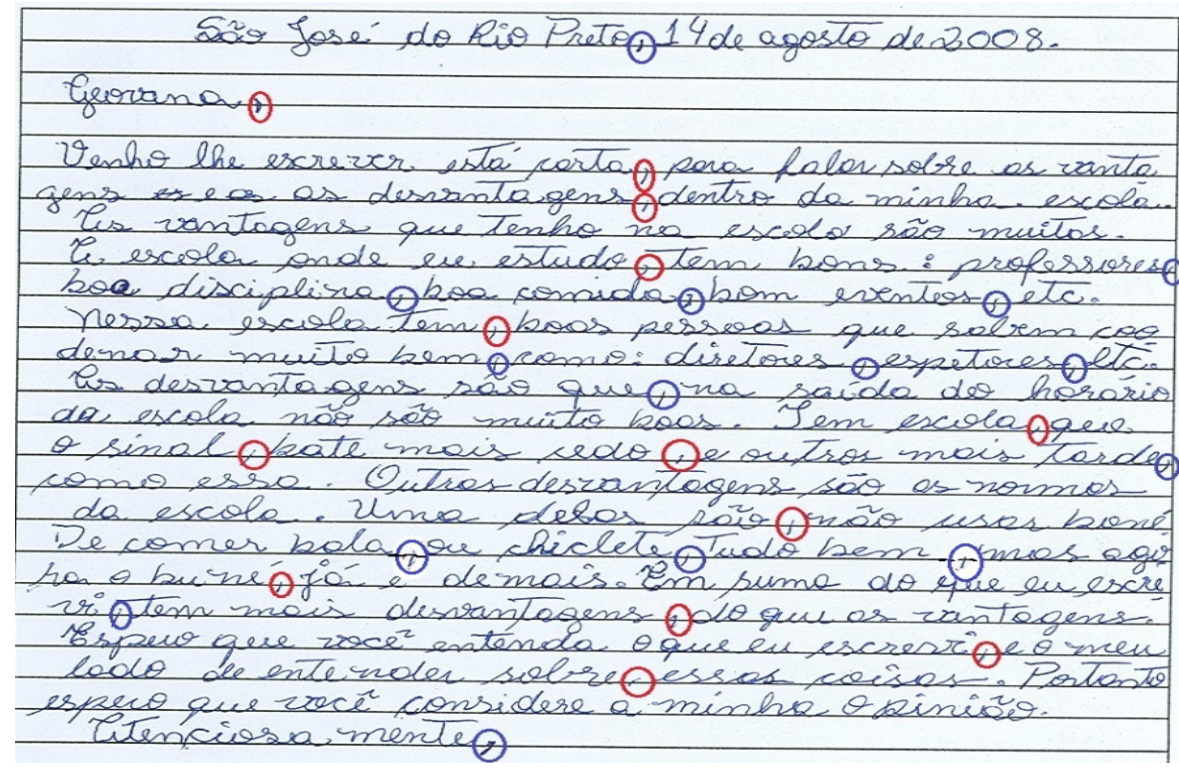

Fonte: Banco de Dados de Escrita do Ensino Fundamental II

\footnotetext{
${ }^{9}$ TENANI, Luciani. Banco de Dados de Escrita do Ensino Fundamental II. Disponível em: http://www.convenios.grupogbd.com/ redacoes/Login. Acesso em: 4 jul. 2016.
} 
No texto, o aluno atende ao solicitado na proposta e escreve uma carta à pesquisadora a fim de avaliar sua escola, apontando quais suas vantagens e desvantagens. A carta é desenvolvida pelo sujeito escrevente a partir da projeção de uma imagem de interlocutor - no caso a pesquisadora em questão - como alguém conhecido e com quem estabelece uma relação que se baseia mais em certa proximidade do que em distanciamento. A projeção de uma relação de proximidade entre ambos se mostra pelo uso do primeiro nome do interlocutor não acompanhado de pronome de tratamento no início da carta e, ainda, pela referência que se faz ao interlocutor com a forma você em: "espero que você entenda o que eu escrevi [...]” e "espero que você considere minha opinião”. ${ }^{10}$

Considerado o tipo de relação estabelecida com o interlocutor, o texto apresenta traços de um relato a um interlocutor conhecido - embora o mais previsível seria projetar um interlocutor distante, pouco conhecido, externo à instituição escolar e com quem se estabeleceria uma relação de formalidade, tendo em vista que a proposta o apresenta enquanto pesquisador. Dentre esses traços, está a impressão de um tom prosaico e cadenciado ao texto, como se o escrevente relatasse, por meio de vários contornos entoacionais suspensivos, as partes que compõem as vantagens e as desvantagens da escola. Esse tom é particularmente marcado pelos vários usos de vírgula ao longo do texto, inclusive por vírgulas não esperadas do ponto de vista da convenção gramatical (é o caso dos usos de vírgula assinalados em vermelho no texto apresentado na Imagem 2), uma vez que, majoritariamente, a posição em que as vírgulas foram empregadas correspondem a fronteiras de frases entoacionais (constituinte prosódico definido, entre outros aspectos, por um contorno entoacional). ${ }^{11}$ Vale observar ainda que, no texto, o conjunto das vírgulas empregadas parece delimitar unidades de tamanhos similares, como se fossem partes simétricas. Não por acaso, vale igualmente considerar uma tendência das línguas de segmentar frases entoacionais que tenham tamanhos relativamente próximos (cf. NESPOR; VOGEL, 1986). Assim, as vírgulas podem ser interpretadas como marcas que registram, na escrita, a organização linguística que se dá no plano prosódico, evidenciando-se, assim, por meio desse exemplo, que a pontuação é um espaço próprio da escrita cuja constituição é atravessada por outros espaços, que estão do lado de fora.

O trecho a seguir é um exemplo do tom cadenciado atribuído ao relato sobre a escola por meio da segmentação de unidades internas ao texto, realizada pelo uso de vírgulas:

(1) “Tem escola, que o sinal, bate mais cedo, e outros mais tarde, como essa”.

A análise do texto apresentada até aqui considerou o movimento em que a pontuação se volta para o interior do texto, ou seja, para a sua atuação no eixo da organização formal das unidades. No entanto, é preciso considerar a atuação da pontuação no movimento para o exterior do texto, movimento que, ao buscar referência no extraverbal, produz sentidos. Para tratar dele, chamo atenção para as desvantagens da escola apresentadas pelo sujeito.

\footnotetext{
${ }^{10}$ Apesar dessa proximidade, o sujeito atende a protocolos formais do gênero ao utilizar local e data, ao iniciar o texto com a expressão genérica venho por meio desta e finalizá-lo com o uso do modalizador atenciosamente. O uso dessas formas evidencia a inserção do sujeito por práticas de letramento.

${ }^{11}$ Para uma definição detalhada e maior aprofundamento sobre esse constituinte prosódico, bem como sobre a relação entre emprego de vírgula e fronteira prosódica, conferir Soncin (2014) e Soncin e Tenani (2015).
} 
Todas as desvantagens elencadas dizem respeito a normas que regulamentam como deve ocorrer o comportamento e a convivência social no interior do ambiente escolar: é o caso do horário de saída dos alunos, considerado tardio, bem como da proibição de mastigar bala ou chiclete em sala de aula e, ainda, de usar boné nesse mesmo ambiente. Vê-se, pois, que, na consideração do escrevente, aquilo que, segundo seu ponto de vista, afeta sua liberdade no espaço escolar é considerado desvantagem: seja a liberdade de sair em horário mais conveniente, seja a de usar boné ou ainda a de consumir bala ou chiclete. Dentre essas interdições, uma em particular causa inconformismo ao sujeito, muito provavelmente, por considerá-la medida demasiado conservadora, já que afeta a liberdade de expressar uma imagem de si por meio do uso de um acessório de vestimenta: trata-se da interdição do uso do boné.

A incompreensão do sujeito e sua discordância em relação à posição da instituição escolar de proibir o uso do boné é interpretada no texto quando se afirma "De comer bala, ou chiclete, tudo bem, mas agora o buné, já é demais”. Nesse trecho, vê-se que uma vírgula foi empregada após boné. Numa interpretação possível, tal vírgula marca a projeção de um acento tonal que, em termos prosódicos, caracterizaria a ênfase dada ao termo boné. Tentemos nós recuperar em nossa memória, considerando nosso trânsito por práticas de oralidade, com que entoação o referido trecho seria produzido vocalmente. Tal ênfase denuncia a expressividade do sujeito escrevente ao revelar sua avaliação negativa, já que, segundo seu ponto de vista, a proibição do boné é um exagero. Sua avaliação é de tal modo negativa que direciona sua conclusão avaliativa: a escola tem mais desvantagens do que vantagens, embora, no desenvolvimento do texto, tenha sido apresentado, quantitativamente, mais vantagens do que desvantagens.

Consideremos que, para tal interpretação, o emprego de vírgulas, particularmente a vírgula empregada após boné, exerce papel central na organização textual, uma vez que evidencia os sentidos mobilizados pelo sujeito escrevente na enunciação escrita, tornando-os acessíveis ao leitor. No entanto, consideremos que o sentido só é completado quando o leitor acessa a posição valorativa do sujeito, que, nesse caso particular, é marcada privilegiadamente pela entoação com que se pronuncia “mas o boné, já é demais”, com acento enfático em boné. Como conclusão, o leitor poderá entender: o sujeito escrevente, embora reconheça os valores positivos de sua escola, se distancia da posição conservadora que essa instituição mantém e se filia àqueles que defendem a escola como espaço mais relacionado à diversidade, representada pela liberdade de, por exemplo, usar um boné, do que à uniformidade.

Por meio dessa análise, procurei exemplificar como a pontuação marca na escrita aspectos prosódicos que, para além do papel formal, são responsáveis por produzir sentido ao evidenciarem a subjetividade e a historicidade do sujeito. Com ela, busquei ilustrar a proposta teórica que desenvolvi neste texto: a pontuação é uma heterotopia, uma vez que o espaço criado pela pontuação no texto escrito remonta necessariamente ao espaço em que se circunscreve, em outro plano, a prosódia e seu funcionamento linguístico-discursivo. A relação entre pontuação e prosódia, portanto, é uma relação heterotópica, segundo a compreensão de que a pontuação é um espaço definido pelo entrecruzamento com o espaço prosódico. Ou seja, é somente a partir do reconhecimento de que a pontuação está fora de si, por se identificar em meio ao espaço prosódico, que se torna possível reconstituir e conceber a realidade da pontuação manifestada na materialidade gráfica da escrita. 


\section{AGRADECIMENTOS}

Agradeço ao Prof. Dr. Manoel Luiz Gonçalves Corrêa pela sugestão de desenvolver a proposta apresentada neste texto. Salvo a ideia inicial, o desenvolvimento teórico, as aproximações e as análises realizadas são todos de minha inteira responsabilidade.

\section{REFERÊNCIAS}

ANIS, J. L’écriture: Théories et descriptions. Bruxelles: De Boeck Université, 1988.

BARBOSA, P. Conhecendo melhor a prosódia: aspectos teóricos e metodológicos daquilo que molda nossa enunciação. Revista de Estudos da Linguagem, Belo Horizonte, v. 20, n. 1, p. 11-27, 2012.

BAKHTIN, M. Estética da criação verbal. 5. ed. São Paulo: Martins Fontes, 2010.

CHACON, L. Ritmo da escrita: uma organização do heterogêneo da linguagem. São Paulo: Martins Fontes, 1998.

CHAFE, W. Punctuation and the Prosody of Written Language. Berkeley: Center for the Study of Writing, 1987.

CORRÊA, M. L. G. O modo heterogêneo de constituição da escrita. São Paulo: Martins Fontes, 2004.

CORRÊA, M. L. G. Espaço e espacialidade na produção escrita escolar: a reflexão linguísticodiscursiva no ensino da escrita. SCRIPTA, Belo Horizonte, v. 16, n. 30, p. 91-113, 2012.

CORRÊA, M. L. G. Bases teóricas para o ensino da escrita. Linguagem em (Dis)curso, Santa Catarina, v. 13, n. 3, p. 481-513, 2013. Disponível em: https://www.scielo.br/pdf/ld/v13n3/03. pdf. Acesso em: 13 jul. 2020.

D'IMPERIO, M.; et al. Intonational Phrasing in Romance: the Role of Prosodic and Syntactic Structure. In: FROTA, S.; VIGÁRIO, M.; FREITAS, M. J. (Ed.). Prosodies: with Special Reference to Iberian Languages. Phonetics \& Phonology Series. Berlin: Mouton de Gruyter, p. 59-97, 2005.

FOUCAULT, M. De outros espaços. In: Conferência proferida no CERCLE D’ÉTUDES ARCHITECTURALES, 1967. Tradução de Pedro Moura. Diacritics, n. 16, v. 1, 1986, publicada em 2005. Disponível em: http:// www.virose.pt/vector/periferia/foucault_pt.html. Acesso em: 10 jul. 2020.

HALLIDAY, M. A. K. A Course in Spoken English: Intonation. Oxford: Oxford University Press, 1970.

HIRST, D.; DI CRISTO, A. (Ed.). Intonation Systems: a Survey for Twenty Languages. Cambridge: Cambridge University Press, 1998.

LADD, R. Defining Prosody. In: Simultaneous Structure in Phonology. Oxford: Oxford University Press, p. 57-84, 2014. 
MIRA MATEUS, M. H. Estudando a melodia da fala: traços prosódicos e constituintes prosódicos. Palavras/Revista da Associação de Professores de Português, n. 28, p. 79-98, 2005.

NESPOR, M.; VOGEL, I. Prosodic Phonology. Dordrecht: Foris Publications, 1986.

SELKIRK, E. Phonology and Syntax: the Relation between Sound and Structure. Cambridge: Cambridge University Press, 1984.

SONCIN, G. C. N. As vírgulas não-convencionais em textos dissertativos produzidos em ambiente escolar: indícios de organização prosódica, evidência dos imaginários sobre a escrita. Revista Estudos Linguísticos, v. 41, n. 2, p. 389-402, 2012.

SONCIN, G. C. N. Divisão enunciativa do/no sujeito: evidências a partir da observação dos usos não-convencionais da vírgula. Filologia e Linguística Portuguesa, São Paulo, v. 15, n. 1, p. 101-126, 2013. DOI: https://doi.org/10.11606/issn.2176-9419.v15i1p101-126. Disponível em: http://www.revistas.usp.br/flp/article/view/76196/79939. Acesso em: 13 jul. 2020.

SONCIN, G. C. N. Língua, discurso e prosódia: estudar o uso da vírgula é restrito? Vírgula!. 2014. 310f. Tese (Doutorado em Estudos Linguísticos) - Instituto de Biociências, Letras e Ciências Exatas, Universidade Estadual Paulista “Júlio de Mesquita Filho”, 2014. Disponível em: https:// repositorio.unesp.br/handle/11449/110527. Acesso em: 13 jul. 2020.

SONCIN, G. C. N.; TENANI, L. E. Emprego de vírgula e prosódia do Português Brasileiro: aspectos teórico-analíticos e implicações didáticas. Filologia e Linguística Portuguesa, São Paulo, v. 17, n. 2, p. 473-493, 2015. DOI: https://doi.org/10.11606/issn.2176-9419. v17i2p473-493.

SONCIN, G. C. N.; TENANI, L. E Emplois de la virgule en Portugais: une réflexion à partir de textes d'écrivains brésiliens. LINX - Révue de Linguistes de l'Université Paris-Ouest Nanterre La Défense, Nanterre/França, v. 75, n. 2, p. 179-198, 2017a. Disponível em : https:// journals.openedition.org/linx/1938. Acesso em: 23 out. 2020.

SONCIN, G. C. N.; TENANI, L. E. Evidences of the role of prosody in argumentative writing: comma uses in texts written by Brazilian students aged 11-14. Journal Writing \& Pedagogy, Equinox Publishing Sheffield/United Kingdom, v. 9, n. 1, p. 77-101, $2017 \mathrm{~b}$.

TENANI, L. E.; SONCIN, G. C. N. O emprego de vírgulas: evidências de relações entre enunciados falados e escritos. In: MARÇALO, M. J. et al. (Ed.). Língua Portuguesa: ultrapassar fronteiras, juntar culturas. Évora: Universidade de Évora, p. 44-65, 2009.

VOLOSHINOV, V. N.; BAKHTIN, M. M. Discurso na vida e discurso na arte: sobre poética sociológica. Tradução de Carlos Alberto Faraco e Cristóvão Tezza. New York: Academic Press, 1976 [1926].

Recebido em: jul. 2020.

Aceito em: out. 2020. 